\title{
Density-distribution patterns of egg parasitoids in freshwater habitats
}

\author{
Filip Harabiš, Martin Šigut \& Aleš Dolný
}

\begin{abstract}
Density-distribution patterns of egg parasitoids in freshwater habitats. - Čas. Slez. Muz. Opava (A), 62 : 65-72, 2013.

Abstract: Similar in effect to predators, egg parasitoids could have a significant effect on the distribution of host and its' population dynamics. However, knowledge about the biology and ecology of aquatic parasitoids and their effects on the host are very limited. The aim of this study was to determine whether the density of parasitoids is affected by several environmental determinants and if there is a temporal change of density during the season, particularly in relation to the host population dynamics (from order Odonata in this study). In total, 266 individuals of parasitoid wasps (from four families utilizing damselflies as hosts) were identified. The density of parasitoids did not change significantly during the season regardless of the population dynamics of model host $L$. sponsa and other odonates, while there was a significant effect of habitat type on the density of parasitoids. This indicates that eggs of Odonata represent only one of several host taxa. This indicates that egg parasitoids of aquatic invertebrates are host generalists preferring open over afforested habitats.
\end{abstract}

Key words: habitat quality, egg parasitism, parasitoids, host-parasitoid dynamics

\section{Introduction}

Although parasitoids are among the largest groups of organisms on Earth, knowledge of their biology, taxonomy and ecology is very limited, especially of the species that are not widely used for purposes of biological pest control. While there are several parasitoid taxa in another six orders (mainly Diptera), most of the parasitoids belong to the order Hymenoptera (Godfray 1994; Footit \& Adler 2009). Whereas almost all hymenopterans are terrestrial, development in aquatic environments has evolved independently in at least 11 families (Bennett 2008). All known species ( $~ ~ 150)$ of aquatic Hymenoptera are parasitoids in which the female enters the water to search for hosts (Bennett 2008). A wide range of aquatic insects and other invertebrates (spiders) are known as hosts of parasitoids (Roble 1985; Fursov 1995). The majority of aquatic parasitoids are host generalists, attacking plenty of hosts from different taxa (Fursov 1995).

Aquatic Hymenoptera are mainly solitary endoparasitoids, preferring the egg life stage and with only one egg developing inside each host (Askew \& Shaw 1986, Bennet 2008). They are classified as idiobionts that attack a host life stage that is immobile (e.g. an egg or pupa) and then consume the host tissues immediately after the parasitization (Askew \& Shaw 1986; Hassell 2000). Developing the abilities to stay underwater, find a host, and undergo further development has required several adaptations (Thorpe 1950; Bennett 2008).

Significant adaptation may be also related to behaviour enabling location of a specific host. Little is known about the foraging behaviour of aquatic egg parasitoids, but several authors have assumed an active search for eggs similar to that seen in terrestrial species (e.g. LaPlante 1975; Corbet 1999). Higher density of hosts can be associated with higher rates of parasitism. Henriquez and Spence (1993) assume that parasitoids may use both visual and chemical cues to locate their hosts. Some observations of foraging behaviour among small scelionid wasp species indicate that these parasitoids use phoresis on female Odonates as a means to reduce costs of movement and especially facilitate the detection of eggs (Clausen 1976; Corbet 1999).

Moreover, the hosts are able to detect parasitoids. Females are able to memorize the risk associated with high density of parasitoids before oviposition (Hirayama \& Kasuya 2009). Hosts are in several ways enabled significantly to reduce the risks of egg mortality due to 
parasitoids, including by physiological defence and, in particular, site selection for oviposition (e.g. Amano et al. 2008; Harabiš et al. unpubl.). Distribution of parasitoids is related to habitat features. The distribution of parasitoids within habitats is non-random and is closely related to the structure and quality of habitat patches (Roland \& Taylor 1997; James et al. 2009; Mlynarek et al. 2011). One of the most frequently mentioned aspects of patch quality is vegetation structure (Roland \& Taylor 1997; Fraser et al. 2007). Significantly lower rates of parasitism occur in low-quality habitats (fragmented patches) than in complex habitat patches (Roland \& Taylor 1997; Holtzschuh et al. 2010). This does not apply to all species, however (Roth et al. 2006).

As parasitoid has an intimate relationship with its host, it also has similarities with classical parasitism (Godfray \& Shimana 1999). Numerous case studies provide evidence of the close relationship between parasites and their hosts (see Møller 2005; Kohler 2008). For example, water mites (Forbes et al. 2008) and gregarines (Forbes et al. 2011) occur mainly during the period when the population densities of hosts are at their highest levels. Yet, the effect of seasonality in host-parasitoid interaction has not been well documented for egg parasitoids. The main aim of the study is to analyse the effect of key factors on overall distribution of aquatic parasitoids and in particular to evaluate temporal changes in predation pressure caused by egg parasitoids.

\section{Material and methods}

\section{Study area}

Sampling took place in six freshwater habitats in the foothills of the Beskydy Mountains (within an area of about $80 \mathrm{~km}^{2}$ ) in the vicinity of the cities Valašské Meziř́íčí and Rožnov pod Radhoštěm in the north-eastern part of the Czech Republic. The individual sites were not significantly different in terms of their water conditions ( $\mathrm{pH}$, conductivity) or altitude (Table 1). Each habitat type was classified with regard to structure of vegetation cover and degree of shading as 1) open habitats (shading < 20\%), 2) fragmented habitats (shading 20-50\%), or 3) habitats with continuous vegetation cover (shading > 50\%) (Table 1). All sites had been uninterruptedly freshwater habitats at least from 2006, were extensively formed by human activities, and contained welldeveloped emergent vegetation. Another criterion for selection of sites was initial occurrence of $L$. sponsa in previous years.

\section{Sampling}

Sampling was carried out during June to September 2011 between 10:00 and 16:00. Adult parasitoid wasps were sampled using Möricke 'pan' traps (Möricke 1951). Yellow and blue pans were installed at sites near the water surface at least $3 \mathrm{~m}$ apart. The installed pan traps were filled with water, with the addition of salt as a preserving agent. To increase the traps' efficiency, detergent was added to reduce surface tension of the water. Eight pan traps ( 4 yellow +4 blue) were placed at each site. At localities where it was not possible to place the specified number of traps without violating the sampling design, lower numbers of traps were installed. This was taken into consideration in the subsequent statistical evaluation.

Colour of pan traps was included as a factor into the analysis mainly because we wanted to eliminate the variability of traps caused by their colour. Yellow pan traps are commonly used for trapping of microhymenoptera parasitoids, but there are several taxa of Hymenoptera (especially pollinators) that are better attracted by different colour plates (mainly blue). The efficiency of yellow pan traps was significantly higher than was that of blue traps. This effect was significant for all families except for Trichogrammatidae (Table 2). Given the low number of trapped individuals in the latter family, it was not possible objectively to evaluate the efficiency of pan traps for that family. Traps were placed at sites in 10-day intervals. After 3-4 days, the content of each trap was filtered and stored in $80 \%$ ethanol for subsequent determination in the laboratory. The parasitoids were identified according to Goulet \& Hubert (1993) and Pitkin (2004).

Additionally we analysed seasonal phenology of damselfly Lestes sponsa, as a potentially important host species. Lestes sponsa is a widespread generalist whose distribution ranges from Western Europe to Japan. The biology of this species is well known, as it often is used as a model species. The period of oviposition occurs in late July and August, and eggs are laid into the stems of macrophyte vegetation. The generation cycle is univoltine. Endophytically laid eggs fall into diapause and the individuals overwinter in the egg life stage. Immediately after laying, the eggs become targets for egg parasitoids that undergo the life cycle before the start of the winter season. 
Table 1: Details of sampling sites (Beskydy Mountains, Czech Republic), including habitat type and overall species richness of Odonata

\begin{tabular}{cccccc}
\hline Locality & \multicolumn{2}{c}{ GPS position } & $\begin{array}{c}\text { Elevation } \\
\text { (m a.s.l.) }\end{array}$ & $\begin{array}{c}\text { Number } \\
\text { species }\end{array}$ & Habitat \\
\hline Loc_01 & $49^{\circ} 25^{\prime} 18.69^{\prime \prime} \mathrm{N}$ & $18^{\circ} 13^{\prime} 18.42^{\prime \prime} \mathrm{E}$ & 450 & 6 & fragmented \\
Loc_02 & $49^{\circ} 27^{\prime} 47.40^{\prime \prime} \mathrm{N}$ & $18^{\circ} 04^{\prime} 42.53^{\prime \prime} \mathrm{E}$ & 340 & 7 & open \\
Loc_03 & $49^{\circ} 27^{\prime} 20.28^{\prime \prime} \mathrm{N}$ & $18^{\circ} 04^{\prime} 02.67^{\prime \prime} \mathrm{E}$ & 335 & 6 & continuous \\
Loc_04 & $49^{\circ} 28^{\prime} 57.64^{\prime \prime} \mathrm{N}$, & $18^{\circ} 02^{\prime} 58.12^{\prime \prime} \mathrm{E}$ & 390 & 2 & continuous \\
Loc_05 & $49^{\circ} 28^{\prime} 05.41^{\prime \prime} \mathrm{N}$ & $17^{\circ} 59^{\prime} 59.69^{\prime \prime} \mathrm{E}$ & 305 & 12 & open \\
Loc_06 & $49^{\circ} 31^{\prime} 08.12^{\prime \prime} \mathrm{N}$ & $17^{\circ} 54^{\prime} 18.95^{\prime \prime} \mathrm{E}$ & 275 & 13 & fragmented \\
\hline
\end{tabular}

Table 2: Effect of variables on density of parasitoids. Number of Lestes refers to abundance of Lestes sponsa. Habitat refers to vegetation structure. Species richness refers to the number of Odonata species. Seasonality refers to date of sampling. Trap colour refers to yellow or blue pan traps.

\begin{tabular}{|c|c|c|c|}
\hline Variable & df & Chi & $P$ \\
\hline \multicolumn{4}{|l|}{ Eulophidae } \\
\hline Number of Lestes & 1 & 0.83 & 0.362 \\
\hline Habitat & 2 & 8.65 & 0.013 \\
\hline Species richness & 1 & 19.08 & 0.141 \\
\hline Seasonality & 6 & 2.16 & 0.004 \\
\hline Trap colour & 1 & 19.08 & $<0.001$ \\
\hline \multicolumn{4}{|l|}{ Mymaridae } \\
\hline Number of Lestes & 1 & 0.00 & 0.977 \\
\hline Habitat & 2 & 10.05 & 0.007 \\
\hline Species richness & 1 & 2.95 & 0.086 \\
\hline Seasonality & 6 & 23.07 & 0.001 \\
\hline Trap colour & 1 & 4.96 & 0.026 \\
\hline \multicolumn{4}{|l|}{ Scelionidae } \\
\hline Number of Lestes & 1 & 3.61 & 0.057 \\
\hline Habitat & 2 & 8.36 & 0.015 \\
\hline Species richness & 1 & 7.08 & 0.008 \\
\hline Seasonality & 6 & 25.60 & $<0.001$ \\
\hline Trap colour & 1 & 10.47 & 0.001 \\
\hline \multicolumn{4}{|l|}{ Sum of parasitoids } \\
\hline Number of Lestes & 1 & 2.36 & 0.125 \\
\hline Habitat & 2 & 17.63 & $<0.001$ \\
\hline Species richness & 1 & 10.00 & 0.002 \\
\hline Seasonality & 6 & 50.71 & $<0.001$ \\
\hline Trap colour & 1 & 25.85 & $<0.001$ \\
\hline
\end{tabular}


Adult individuals of L. sponsa were sampled according to timed survey method (Kadlec et al. 2012). For this purpose were searched specific habitats, especially macrophyte vegetation in order to catch as many individuals over time. To avoid duplicate counting, the specimens were collected and later released. All localities were sampled at equal intervals $(0.5 \mathrm{~h}$ for each locality) to obtain precise comparable estimates. During the sampling we have also recorded the occurrence of other species of Odonata as model organisms (presence/absence only) that were identified according to Dijkstra \& Lewington (2006).

\section{Statistical analysis}

Non-linear mixed-effects models (NLME) with Poisson error distribution (link $=\log$ ) were used to analyse the effects of vegetation structure, density of L. sponsa and the overall species richness of Odonata on the abundance of parasitoids (by individual families). The effect of sampling period (seasonality) was also included in the model. Given the small number of individuals found within it, the family Trichogrammatidae was not analysed separately. In order to reflect the site differences and different number of traps at each site, a split-plot design was selected (Bates et al. 2011). In the model, L. sponsa density, overall species richness, and vegetation structure were treated as fixed effects and locality as the random effect. Individual traps as sub-units were nested in locality. To analyse differences in the efficiency of pan traps, colour was used as a fixed effect. Within NLME, we used the glmer function, which is a part of the lme4 package (Bates et al. 2011).

To find the minimum adequate model, all non-significant variables $(\mathrm{P}>0.05)$ were excluded step-by-step, using the backward selection procedure (Crawley 2007). The model selection was based on AIC criterion (Crawley 2007). Each minimal adequate model was verified using standard statistical diagnostics in the end, i.e. by residuals and standardized residuals versus fitted and predicted values and by Cook's distances (Crawley 2007). Post hoc comparisons of pairwise differences between the number of parasitoids for each habitat type were made using the multiple comparisons of means: Tukey contrasts; Multcomp package in R (Bretz et al. 2010). All analyses were performed using the statistical program R 2.15.0 (R Development Core Team 2011).

\section{Results}

In total, 266 egg parasitoid individuals were found during the study. The most abundant parasitoid family comprised the Scelionidae (119 individuals), followed by Mymaridae (71) and Eulophidae (65). The least abundant family was Trichogrammatidae, in which only 11 individuals were found (Fig. 1).

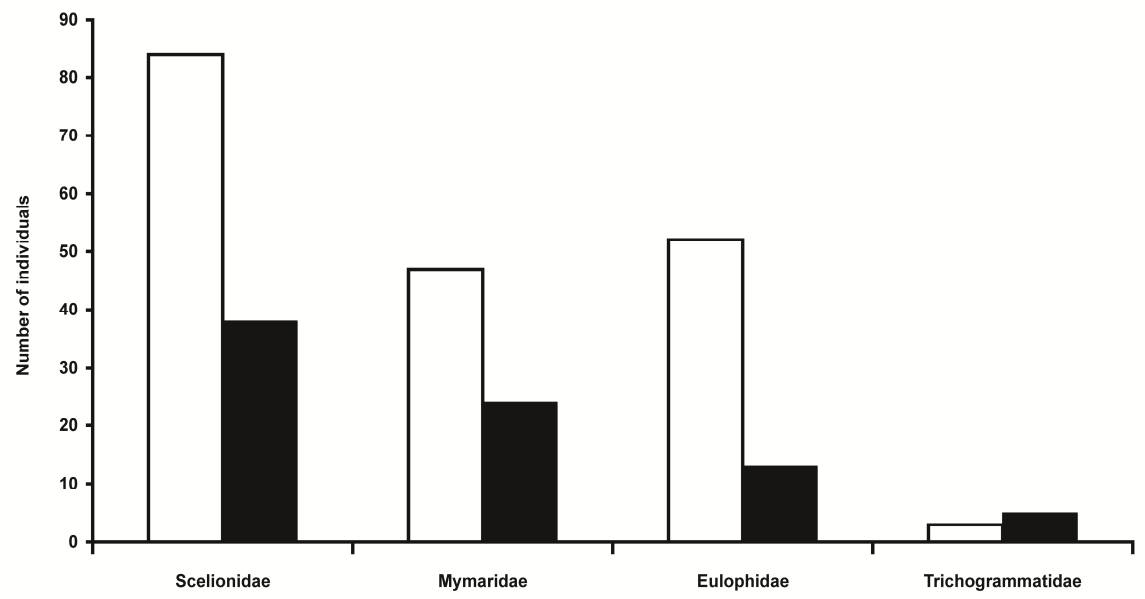

Fig 1: Total number of parasitoid wasps found in pan traps. White columns denote yellow pan traps, while black column denotes blue pan traps.

There was no significant relationship was found between the number of parasitoids (all families) and the recorded abundance of L. sponsa (Table 2). Possible linkage (but one not determined to be statistically significant) to the abundance of $L$. spons $a$ was found in the family Scelionidae (Table 2). High numbers of parasitoids were found even at sites where there was no documented occurrence of L. sponsa in the year of the survey (but had been 
documented in previous years). Effect of seasonality on the abundance of parasitoids was significant for all families (Table 2). A similar trend was observed in the recorded occurrence of Odonata and was probably caused by significant changes in temperature during the season. Except for the families Mymaridae and Eulophidae, there was significant correlation between the number of parasitoid wasps and the species richness of Odonata (Table 2). However, the sampling design did not allow for differentiating whether this was a coincidence of parasitoids and Odonata or it was caused by interaction between hosts (Odonata) and their parasitoids.

The density of parasitoids (from all families) was significantly affected by habitat type (Table 2). The gradual gradient of parasitoid density in the direction: open > fragmented >> continuous tree cover indicates that parasitoids had a considerable preference for open habitats over continuously afforested habitats. For the sum of parasitoids, this trend was significant between continuous : open $(\mathrm{t}=-3.63, P<0.001)$ and continuous : fragmented $(\mathrm{t}=$ $-4.57, P<0.001)$ habitats, while there was no difference in the case of open : fragmented habitats $(\mathrm{t}=0.78, P=0.695)$. The strength of this relationship was significantly different between families. In the family Mymaridae, there was a similar trend for the sum of parasitoids in the cases of continuous : open $(\mathrm{t}=-2.57, P=0.025)$ and continuous : fragmented $(\mathrm{t}=-3.64, P<0.001)$ habitats, but there was no significant relationship for open : fragmented $(\mathrm{t}=0.315, P=0.940)$. There was a significant gradient in the family Scelionidae. The highest density of these wasps was in open habitats [open : continuous $(\mathrm{t}=3.11, P=$ $0.004)$; open : fragmented $(\mathrm{t}=2.40, P=0.037)$ ], while the lowest density was in continuously afforested habitats [continuous : fragmented $(\mathrm{t}=-2.55, P=0.024)]$. Post hoc tests did notshow significant differences between habitat types in the family Eulophidae.

\section{Discussion}

This study demonstrates that the density of egg parasitoids is affected mainly by habitat type (in particular vegetation cover) but not by the abundance and seasonal dynamics of their host (e.g. Odonata). The initial assumption that the oviposition strategy of individual host taxa leads to a very close linkage in host-parasitoid population dynamics and therefore that the density of parasitoids should correlate with the occurrence of their hosts and the period of hosts' oviposition probably does not apply for egg parasitoids of Odonata.

Except for a period of unsuitable weather conditions (mainly characterized by a significant decrease in temperature), the density of parasitoid wasps (all monitored families) did not change significantly throughout the season. This suggests that egg parasitoids are able to use a wide range of hosts for their development. This finding has appeared across multiple studies concerned with parasitoids of aquatic invertebrates (see Fursov 1995; Corbet 1999; Bennett 2008). They are idiobionts, that attack their hosts always at the time of oviposition and usually parasitize yet undifferentiated tissues and do not need adaptations enabling them to overcome the mechanical and physiological defence of their hosts (Askew \& Shaw 1986). There is no pressure, therefore, for egg parasitoids to specialize on single host taxa, and idiobionts are able to attack a wider range of hosts than are koinobionts (Althoff 2003). Thus, we assume that L. sponsa (endophytically laid eggs) and other odonates are not the main hosts, but rather constitute just one of many host taxa.

The question remains how wasps detect endophytically laid eggs, and especially those laid underwater. LaPlante (1975) describes foraging behaviour of parasitoid wasps as a random process in which a female seeks for eggs laid on vegetation. It can be assumed that the parasitoids are better able to detect eggs enclosed within vegetation. This does not require specialization upon single taxa, however, since most aquatic invertebrates prefer aquatic plants for oviposition (Footit \& Adler 2009).

This study shows that there is a strong linkage of parasitoids on vegetation and habitat type. These aspects are most often cited as factors affecting the distribution of parasitoids (e.g. 
Roland \& Taylor 1997; Fraser et al. 2007). Similar to the situations for other invertebrates, while rich vegetation cover may be important for several species of parasitoids it may represent a barrier to other species (Roth et al. 2006). Based on the results of our study, it can be assumed that aquatic parasitoids fall into the second category, namely that they prefer more open habitats. In order to work through the potentially general applicability of this trend, it is necessary to extend the research to a larger number of sites.

The results of this study suggest that the density of parasitoids was positively correlated with the species richness of Odonata, but the cause of this correlation is unresolved. As mentioned earlier, the distribution of parasitoids is closely related to vegetation structure (Roland \& Taylor 1997). But this applies also to the order Odonata (e.g. Corbet 1999; Sahlén \& Ekestubbe 2001). Although it can be assumed that the densities of Odonata and aquatic egg parasitoids are closely associated with habitat quality (mainly vegetation structure), the methodology of this study did not allow us to distinguish whether this was only coincidental for the two ecological groups or if this was due to the host-parasitoid relationship.

With the possible exceptions of several groups of parasitoids attacking pests of economically important crops, there is but very limited information about the behaviour and ecology of parasitoids. This scarcity ensues from the low level of knowledge about the taxonomy of micro-hymenoptera. Moreover, there is still little known about the significance of key environmental factors on the distribution of aquatic parasitoids. Future research should examine also the adaptation of other hosts as well as additional attributes of the hostparasitoid relationship.

Acknowledgements: This paper was written in connection with an Institute of Environmental Technologies project, reg. no. CZ.1.05/2.1.00/03.0100 supported by the Research and Development for Innovations, Operational Programme financed by the Structural Funds of the Europe Union. The study was funded by Grant No. SGS11/PRF/2011 from the University of Ostrava and Grant No. 42110/1312/3118 from the Internal Grant Agency of Czech University of Life Sciences Prague. We would like to thank V. Fursov (Ukrainian National Academy of Sciences) and P. Janšta (Charles University in Prague) for their help with determination of parasitoids.

\section{References}

Althoff D. M. (2003): Does parasitoid attack strategy influence host specificity? A test with new world braconids. - Ecological Entomology 28: 500-502.

Amano H., Hayashi K. \& Kasuya E: (2008): Avoidance of egg parasitism through submerged oviposition by tandem pairs in the water strider, Aquarius paludum insularis (Heteroptera: Gerridae). - Ecological Entomology 33: 560-563.

Askew R.R. \& Shaw M.R. (1986): Parasitoid communities: their size, structure and development, pp. 225-264. In: Waage J. \& Greathead D. [eds]: Insect Parasitoids, Academic Press, London, 389 pp.

Bates D., Maechler M. \& Bolker B. (2011): Fit linear and generalized linear mixed-effects models. R package version 0.999375-35 lme4: Linear mixed-effects models using S4 classes. R package version 0.999375-39. http://CRAN.R-project.org/package=lme4.

Bennett A.M.R. (2008): Global diversity of Hymenopterans (Hymenoptera; Insecta) in freshwater. Hydrobiologia 595: 529-534.

Bretz F., Hothorn T. \& Westfall P. (2010): Multiple Comparisons Using R. Chapman and Hall/CRC.

Clausen C. P. (1976): Phoresy among entomophagous insects. - Annual Review of Entomology 21: 343-368.

Corbet P.S. (1999): Dragonflies: Behavior and Ecology of Odonata. Harley Books, Colchester, 864 pp.

Crawley M.J. (2007): The R Book. Wiley-Blackwell, Chichester, 1076 pp.

Dijkstra K.-D.B. \& Lewington R. (2006): Field guide to the dragonflies of Britain and Europe.Wildlife Publishing, Dorset, 320 pp.

Footit R.G. \& Adler P.H. (2009): Insect Biodiversity: Science and Society. Wiley-Blackwell, Chichester, 656 pp.

Forbes M.R., Mlynarek J.J., Allison J. \& Hecker K.R. (2011): Seasonality of gregarine parasitism in the damselfly, Nehalennia irene: understanding unimodal patterns. - Parasitology Research 110: 245-250.

Forbes M.R. \& Robb T. (2008): Testing hypotheses about parasite-mediated selection using odonate hosts, pp. 175-188. In: Cordoba - Aguilar A. [ed.]: Dragonflies: model organisms for ecological and evolutionary research. Oxford University Press, New York, 304 pp. 
Fraser S.E.M., Dytham C. \& Mayhew P.J. (2007): Determinants of parasitoid abundance and diversity in woodland habitats. - Journal of Applied Ecology 44: 352-361.

Fursov V.N. (1995): A review of Chalcidoidea (Hymenoptera) parasitizing the eggs of aquatic insects in Europe. - Bulletin of Irish Biogeographical Society 18: 2-12.

Godfray H.C.J. (1994): Parasitoids, behavioral and evolutionary ecology. Princeton University Press, New Jersey, 488 pp.

Godfray H.C.J. \& Shimada M. (1999): Parasitoids as model organisms for ecologists. - Research on Population Ecology 41: 3-10.

Goulet H. \& Hubert J.F. (1993): Hymenoptera of the world. An identification guide to families. Research Branch, Agricultural Canada Publication, Canada Communication Group-Publishing, Ottawa, 668 pp.

Hassell M.P. (2000): The Spatial and Temporal Dynamics of Host-Parasitoid Interactions. Oxford University Press, Oxford, $208 \mathrm{pp}$.

Henriquez N.P. \& Spence J.R. (1993): Host location by the gerrid egg parasitoid Tiphodytes gerriphagus Marchal. - Journal of Insect Behavior 6: 455-466.

Hirayama H. \& Kasuya E. (2009): Oviposition depth in response to egg parasitism in the water strider: high risk experience promotes deeper oviposition. - Animal Behaviour 78: 935-941.

Holtzschuh A., Steffan - Dewebter I. \& Tscharntke T. (2010): How landscape composition and configuration, organic farming and fallow strips affect the diversity of bees, wasps and their parasitoids. Journal of Animal Ecology 79: 491-500.

James J.A., Bert D.G. \& Forbes M.R. (2009): Wetland type differentially affects ectoparasitic mites and their damselfly hosts. - Ecography 32: 800-806.

Kadlec T., Tropek R. \& Konvička M. (2012): Timed surveys and transect walks as comparable methods for monitoring butterflies in small plots. - Journal of Insect Conservation 16: 275-280.

Kohler S. (2008): The Ecology of Host-Parasite Interactions in Aquatic Insects, pp. 55-80. In: Lancaster J. \& Briers R.A. [eds]: Aquatic Insects Challanges to Populations, Proceedings of the Royal Entomological Society's 24th Symposium. CABI, 332 pp.

Laplante J.-P. (1975): Observations sur la ponte de quatre odonates du genre Lestes (Zygoptera: Lestidae) au Québec. - Le Naturaliste canadien 102 : 279-292.

Mlynarek J.J., Bert D.G., Peralta - Vázquez G.H., James J.A. \& Forbes M.R. (2011): Relationships Between Gregarine Infection in Damselflies, Wetland Type, and Landscape Characteristics. - The Canadian Entomologist 143: 460-469.

Møller A.P. (2005): Parasitism and the regulation of host populations, pp. 43-53. In: Thomas F., Renaud F. \& Guéguan J.-F. [eds]: Parasitism and ecosystems. Oxford University Press, New York, 232 pp.

Möricke V. (1951): Eine Farbfalle zur Kontrolle des Fluges von Blattlausen, insbesondere der Pfirsichblattlaus Myzodes persicae (Sulz.). - Nachrichtenblatt des Deutschen Pflanzenschutzdienste (Braunschweig) 3: 2324.

Pitkin B.R. (2004): Universal Chalcidoidea Database - a key to the families of Chalcidoidea and Mymaromatoidea. The Natural History Museum in London. Internet link: http://www.nhm.ac.uk/researchcuration/research/projects/chalcidoids/mymaridae.html.

R Development Core Team (2011): R: A language and environment for statistical computing. R Foundation for Statistical Computing, Vienna. Internet link: http://www.R-project.org.

Roble S. (1985): Submergent capture of Dolomedes triton (Araneae, Pisauridae) by Anoplius depressipes (Hymenoptera: Pompilidae). - The Journal of Arachnology 13: 391-392.

Roland J. \& Taylor P.D. (1997): Insect parasitoid species respond to forest structure at different spatial scales. - Nature 386: 710-713.

Roth D., Roland J. \& Roslin T. (2006): Parasitoids on the loose - experimental lack of support of the parasitoid movement hypothesis. - Oikos 115: 277-285.

Sahlén G. \& Ekestubbe K. (2001): Identification of dragonflies (Odonata) as indicators of general species richness in boreal forest lakes. - Biodiversity and Conservation 10: 673-690.

Thorpe W.H. (1950): Plastron respiration in aquatic insects. - Biological Reviews 25: 344-390. 


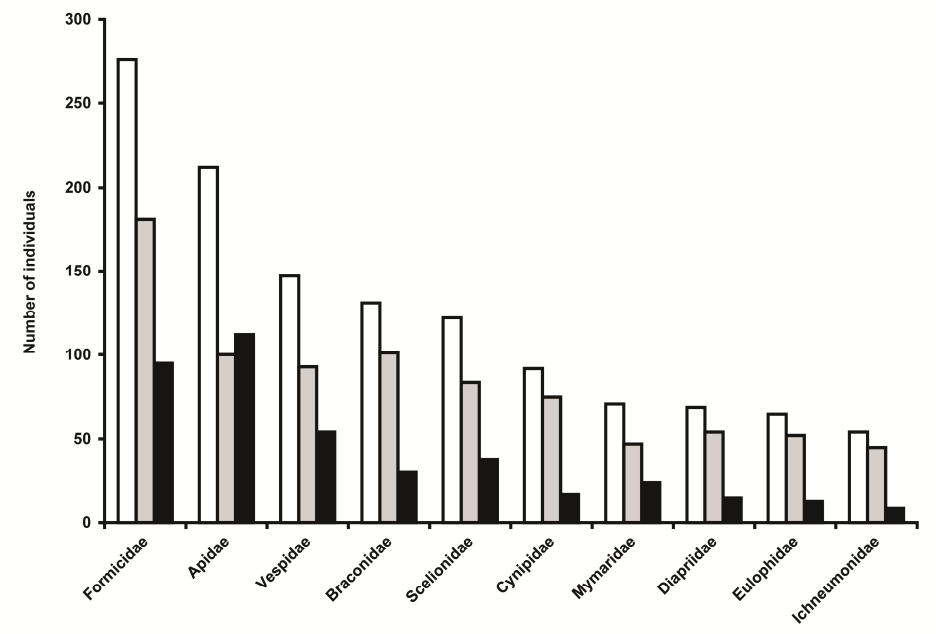

Appendix 1: Ten most abundant families of Hymenoptera trapped in pan traps. White columns denote yellow pan traps, black columns denote blue pan traps, and hatched columns denote sum of individuals.

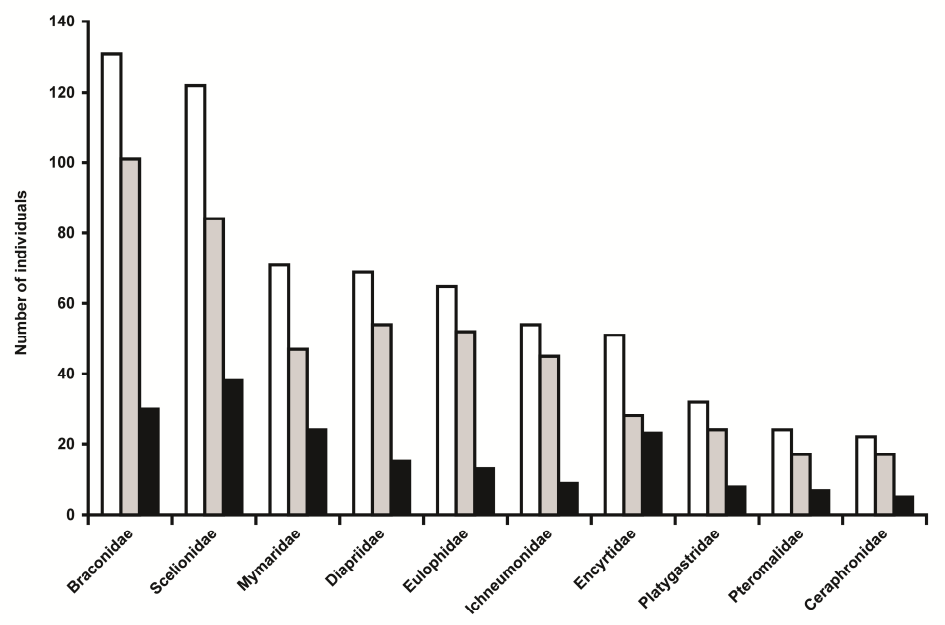

Appendix 2: Ten most abundant parasitoid families of Hymenoptera trapped in pan traps. White columns denote yellow pan traps, black columns denote blue pan traps, and hatched columns denote sum of individuals.

Authors' addresses: Filip Harabiš, Department of Ecology, Faculty of Environmental Sciences, Czech University of Life Sciences Prague, CZ-165 21 Prague 6, Czech Republic.

E-mail: harabis.f@gmail.com

Martin Šigut, Department of Biology and Ecology / Institute of Environmental Technologies, Faculty of Sciences, University of Ostrava, CZ-710 00 Slezská Ostrava, Czech Republic. E-mail: marton.sigut@gmail.com

Aleš Dolný, Department of Biology and Ecology / Institute of Environmental Technologies, Faculty of Sciences, University of Ostrava, CZ-710 00 Slezská Ostrava, Czech Republic. E-mail: ales.dolny@osu.cz 